\title{
ARTHUR SCHNITZLER, O DUPLO DE FREUD, E O CONCEITO DE HISTERIA EM SENHORITA ELSE E CRÔNICA DE UMA VIDA DE MULHER
}

\author{
Érica Schlude Wels \\ Profa. Adjunta Língua e Literatura Alemã - Departamento de Letras Anglo-Germânicas da \\ Faculdade de Letras - UFRJ \\ schludew@gmail.com
}

\section{RESUMO}

No presente artigo, faz-se uso da literatura como lócus privilegiado de produção de saberes, sem se opor à noção de verdade ou de realidade. Nesse sentido, acreditase que a literatura antecipa saberes e dá voz a discursos marginais. A cidade de Viena da virada do século XIX para o XX traduz o Zeitgeist (espírito da época), pois, centro da modernidade artística, cultiva grande interesse pelos temas do mundo interior e apresenta, em seu desenvolvimento social e arquitetônico, modernidade e tradição. A decadência da ordem imperial entra em choque com as novas correntes de pensamento, configurando um Ortgeist (espírito de lugar) marcado pela ambivalência. Nesse manancial, desenvolvem-se as obras de Sigmund Freud (1856-1939) e Arthur Schnitzler (1862-1931), este o duplo (Doppelgänger) do Pai da Psicanálise. $\mathrm{Na}$ obra de Schnitzler, o conceito de histeria ganha voz e corpo nas personagens Else, de Senhorita Else (1924), e Therese, de Crônica de uma Vida de Mulher (1928).

Palavras-chave: Viena, histeria, Schnitzler.

\section{ZUSAMMENFASSUNG}

Der vorliegenden Artikel verwendet Literatur als privilegierter Ort der Wissensproduktion, ohne dem Gedanken von Wahrheit oder Realität zu widersprechen. In diesem Sinne wird angenommen, dass die Literatur Wissen antizipiert und marginalen Diskursen eine Stimme gibt. Das Wien der Jahrhundertwende vom 19. zum 20. Jahrhundert repräsentiert den Zeitgeist (Kultur der Wiener Moderne), ist somit Zentrum der künstlerischen Moderne, vergeistigt deren großes Interesse an den Themen der inneren Welt und präsentiert in seiner sozialen und architektonischen Entwicklung Modernität und Tradition. Die Dekadenz der kaiserlichen Ordnung kollidiert mit den neuen Denkströmungen und bildet einen von Ambivalenz geprägten Ortgeist. Aus dieser Quelle gehen Werke von Sigmund Freud (18561939) und Arthur Schnitzler (1862-1931) hervor - der Doppelgänger für den Begründer der Psychoanalyse. In Schnitzlers Werk gewinnt der Begriff der Hysterie in den Charakteren der Else aus Fräulein Else (1924) und von Therese aus Therese. Chronik eines Frauenlebens (1928) Stimme und Körper.

Schlüsselwörter: Wien, Hysterie, Schnitzler. 
O período conhecido como Wiener Moderne, isto é, a Modernidade Vienense (aqui, consideramos o interregno que vai de 1890 a aproximadamente 1910), é um terreno atravessado por crises e rupturas. Estas duas décadas constituem-se no resultado das mutações políticas, sociais e culturais iniciadas com as revoluções de 1848 , e cujo prolongamento permanece sensível em Viena até 1938, ano da Anschluss, isto é a anexação da Áustria à Alemanha nazista (LE RIDER, 1993, p. 23). Durante a Wiener Moderne, vários campos de saber reúnem-se em movimentos de crítica e renovação: positivismo e epistemologia, em Ernst Mach (1839-1916); fenomenologia e filosofia da linguagem, em Franz Brentano (1838-1917); psicanálise, em Sigmund Freud (1856-1939); história da arte, em Alois Riegel (1858-1905) e Franz Wickhoff (1853-1909); literatura, em a "Jovem Viena", de Hugo von Hofmannsthal (1874-1929), Arthur Schnitzler (1862-1931), Karl Kraus (18741936) e Hermann Bahr (1863-1934); artes plásticas, em Gustav Klimt (1862-1918) e a Secessão, artes decorativas e Wiener Werkstätte; erupção do expressionismo, em Oskar Kokoschka (1886-1980) e Egon Schiele (1890-1918); arquitetura, em Otto Wagner (18411918) e Adolf Loos (1870-1933); música, em Gustav Mahler (1860-1911) e Arnold Schönberg (1874-1951); política, no nascimento do antissemitismo moderno e do sionismo; isto somente para citar alguns nomes e tendências mais representativas.

É importante mencionar que alguns traços específicos desta modernidade se explicam pela situação sociocultural da monarquia austro-húngara. Neste cenário, convivem o efeito de atraso, com o ímpeto de se recuperar o tempo perdido: "comparada com outras grandes capitais europeias como Londres, Paris ou Berlim, Viena desempenha, no final do século XIX, o papel de retardatária. (...) Este atraso pode também pode ser observado no campo cultural" (LE RIDER, 1993, p. 24). 
Historicamente, a Viena da Frühe Moderne, da passagem para o Modernismo, assiste à derrocada do Império dos Habsburgo, enquanto continua a crescer e se renovar. No período de 1848 a 1914, a história econômica registra certo atraso na modernização econômica vienense, em comparação com duas outras capitais importantes do mesmo período, Budapeste e Berlim. A decadência deve-se, em primeiro lugar, a problemas da vida política em Viena e da monarquia, evidenciando-se o contraste entre um estilo de governo neoabsolutista carregado de traços arcaicos e uma sociedade largamente modernizada:

A antipatia pessoal do imperador Franz-Joseph em relação a todas as manifestações da vida moderna, sua aversão pelo telefone, o automóvel, os elevadores, o banheiro, a luz elétrica, como também pela arquitetura e pintura contemporânea são lendárias e simbolizam as contradições desse estado que a menor mudança parece ameaçar (Idem, p. 37).

No contexto social e político, o "Mito Habsburguês", isto é, uma ideologia supranacional que deveria ter reunido as nacionalidades, apresenta-se fissurado: manifestações pangermanistas dos nacionalistas alemães, xenofobia em relação à colônia tcheca, propagação do antissemitismo, fazem de Viena "mais um campo de batalha das nacionalidades do que um enclave multinacional” (Idem, p. 38).

Se as mutações ocorridas, desde meados do século XIX, em várias esferas sinalizam a decadência dos Habsburgo, a Primeira Grande Guerra (1914-1918) sela a despedida da ordem monárquica e do Império Austro-Húngaro. Hofmann (1996) compara os novos tempos à história de uma família que, longe da opulência econômica do passado, passa a habitar uma residência sem aquecimento e oferecer, nas refeições, pão e batatas. Para os vienenses, a nova ordem significa a perda da segurança do velho mundo, como expresso por Stefan Zweig (1881-1942), em sua autobiografia, O mundo de ontem ([1942], 2014): 
Ao tentar encontrar uma definição prática para o tempo antes da Primeira Guerra Mundial, no qual me criei, espero acertar dizendo: foi a época áurea da segurança. Tudo na nossa monarquia austríaca quase milenar parecia estar fundamentado na perenidade (...) (2014, p. 19).

A exemplo de outras cidades históricas europeias, Viena se viu reduzida à sombra do que tinha sido, aprendendo a viver com recursos reduzidos. O imperador Carlos, sucessor do querido Imperador Francisco José, propôs que o Império se transformasse em uma confederação de estados com governos autônomos. Líderes tchecos, eslovacos, húngaros, poloneses, croatas, eslovenos e italianos, em regiões que haviam pertencido à velha monarquia imperial, ignoraram o manifesto e seguiram destinos políticos diferentes. Com 54 milhões de habitantes no começo da Primeira Guerra, segunda potência da Europa em termos de território e terceira em população, Viena tornou-se a capital de uma república pequena e empobrecida, registrando $1 / 8$ da superfície e 1/9 da população da antiga ÁustriaHungria. No começo de novembro de 1918, o imperador Carlos renunciou a "qualquer papel nos negócios do Estado". Posteriormente, em 12 de novembro de 1918, a Assembleia Nacional Provisória votou uma lei que proclamava, em seu artigo 1ํ, que a "Áustria alemã é uma república democrática".

Registrando os acontecimentos da virada do século, a Ringstraße, Rua do Anel, na verdade uma longa avenida no coração de Viena, é um símbolo das novas feições da cidade. Segundo Tavares (2007), ela “(...) dará margem a uma transformação urbana de uma rapidez jamais vista (...)" (2007, p.59). Em sua arquitetura de época incerta, alternando todos os estilos, e em seu formato circular, a Ringstraße já parece nos denunciar um fim-da-história" (Idem). 
A expressão criada pelo professor de Economia Política Internacional da Johns Hopkins University, nos Estados Unidos, Francis Fukuyama (1952- ), e que dá título ao seu primeiro livro O fim-da-história e o último homem (1991), é usada, aqui, em sentido diverso. A leitura de Fukuyama aponta para o momento em que o mundo apresenta crises ideológicas no final do século XX, como a perda do espaço político do socialismo (KANAAN, 2005). O que queremos destacar é o término de uma história linear, anunciada pela chegada da modernidade, sob o signo da ambivalência. A tendência ao avanço (Überwindung), em diversos setores, como define o crítico Hermann Bahr, entra em choque com a permanência do antigo. O arquiteto Otto Wagner, no tratado de 1895, Moderne Architektur, declara encerrado o tempo do historicismo eclético das construções de estilo neo (neo-helenístico, neo-romano, neo-renascimento, neoflamengo, neogótico, neobarroco) da Ringstrasse. De acordo com Wagner, é necessário reclamar algo novo e refutar o antigo, adaptando a arquitetura ao progresso técnico. Por outro lado, os poderes austríacos não fornecem a Wagner os meios de realizar suas maiores ambições, recusando projetos do Museu da cidade de Viena, por exemplo, e mostrando o fracasso da modernidade arquitetônica (LE RIDER, 1993, p. 44).

Na linhagem artístico-literária, que tem como um de seus expoentes o escritor Arthur Schnitzler, surge uma forte corrente amoralista, uma espécie de Gefühlskultur, cultura do sentimento. Ao contrário da cultura alemã tradicional, a cultura austríaca não era moral, filosófica ou científica, mas sobretudo estética. Isso conferia aos intelectuais judeus uma outra via de assimilação cultural que não a política: a arte e até a ciência lidas através do estético. 
Sendo assim, sob o signo da ambivalência, Viena desempenha simultaneamente o papel de centro da modernidade e de "laboratório de ensaio para o fim do mundo", como expresso pelo crítico Karl Kraus.

\title{
FREUD, VIENA, PRIMÓRDIOS
}

Para Roudinesco (2000), o Complexo de Édipo e a decadência do poder paterno estariam imbricados à Viena de Sigmund Freud:

\begin{abstract}
Forjado por Freud, o modelo edipiano tinha como pano de fundo a sociedade vienense do fim do século, atormentada por sua própria agonia, por sua sensualidade vergonhosa e por seu culto à atemporalidade. Não somente os pais perdiam a sua autoridade à medida que a monarquia dos Habsburgo progressivamente afundava sob o peso de sua arrogância, quanto o corpo das mulheres parecia ameaçado pela irrupção de um possante desejo de gozo (ROUDINESCO, 2000, p.160).
\end{abstract}

A cidade de Viena, a partir dos pontos levantados anteriormente, configura-se não só como um Zeitgeist, mas também como, na expressão de Tavares (2007), um Ortgeist, isto é, um espírito de localidade.

Na linha da crise de identidade e da ruptura, as ideias de Freud introduzem inquietação nas noções de permanência, continuidade e coesão tradicionalmente ligadas à ideia de unidade do sujeito. O surgimento do conceito de inconsciente, como relido por Lacan, desloca a idealização do sujeito cartesiano, desmontando o cogito "penso, logo existo", para o enunciado "penso onde não sou, logo sou onde não penso" (LACAN, 1998, p.521).

\section{FREUD E SCHNITZLER, CONTERRÂNEOS, CONTEMPORÂNEOS}

Arthur Schnitzler foi um dos maiores tradutores, na literatura e no palco, da moral burguesa que marcou o século XIX. Nascido em 1862, estudou Medicina na Universidade de Viena. Já formado, começou a trabalhar como assistente de Theodor Meynert, psiquiatra 
alemão que fez carreira na Áustria. Três anos antes, nessa mesma instituição, estagiou o jovem Sigmund Freud.

No âmbito da Germanística, o autor vienense é considerado aquele que inaugura o monólogo interior na literatura, com a novela Leutnant Gustl (Tenente Gustl, 1906), onde a problemática nacional não se apresenta pela descrição do panorama político, mas sim nos devaneios de um jovem tenente defrontado com a possibilidade de um duelo, por ter sua honra ameaçada (TAVARES, 2007, p. 63).

Na visão de Schorske (1988), os dois fios da cultura fin-de-siècle austríaca - o estético e o moralista-científico - estavam presentes na biografia de Schnitzler, em proporções praticamente iguais. Fora o pai de Schnitzler, médico de renome, que encaminhara o filho à carreira científica. Convivendo com grandes artistas vienenses como amigos e pacientes, Schnitzler desenvolve, na expressão de Schorske, uma "febre estética aguda" (1988, p. 32), sentindo a premência de uma vocação literária, o que resulta na ferrenha oposição do pai diante de um possível projeto artístico.

A vida literária de Schnitzler teve início durante seus anos de formação universitária, quando escreveu contos e ensaios. Sentia-se dividido entre as letras e a medicina. Com a morte do pai, abandonou a prática médica e pôde dedicar-se plenamente à literatura.

As biografias de Sigmund Freud e Arthur Schnitzler contêm muitos pontos em comum: judeus, médicos, vienenses, além de compartilharem o mesmo círculo de amigos. De início, ambos atuaram na medicina, para, a seguir, Freud se deslocar para a Psicanálise e Schnitzler para a Literatura. Escandalizaram a sociedade da época com seus escritos a respeito da sexualidade humana. É bastante conhecida a frase de Freud, na ocasião dos 60 
anos de Schnitzler, em carta de 14/05/1922: "Penso que eu tenha evitado o contato convosco devido a uma espécie de medo do duplo". Outro registro bastante citado é o comentário de Freud de que Schnitzler ficaria sabendo, através da intuição, tudo aquilo que ele somente podia descobrir por meio de penoso trabalho na clínica. Apesar das similaridades, o escritor-médico e o médico-escritor encontraram-se poucas vezes e trocaram cerca de dez cartas, o que parece corroborar certa distância entre os dois, a despeito da apregoada identidade.

Schorske (1988), em seu capítulo sobre Schnitzler, ressalta a tensão entre a herança paterna de valores moralistas e a convicção moderna de se acreditar numa vida de instintos. Assim, a exemplo de Freud, “(...) resolveu sua ambivalência separando a perspectiva científica de sua matriz moralista, levando-a ousadamente para a vida dos instintos" (Schorske, 1988, p. 32).

Em Das Unheimliche (O Estranho), o duplo remete ao movimento do desejo, a desejos recalcados. Este Unheimlich não é, na realidade, nada de novo ou estrangeiro, mas alguma coisa que é para a vida psíquica familiar e que se tornou estrangeira pelo processo de recalcamento. Esse contato com o recalcamento esclarece a definição de Schelling, segundo a qual o estranho seria alguma coisa que deveria ter ficado na sombra, mas que acabou saindo dela.

Schnitzler, como "duplo" de Freud, ao contrário deste, circulou pela Viena noturna e sedutora, colecionando galanteios e casos amorosos. Povoou sua obra de problemas que certamente testemunhou. Frequentador do círculo literário Jung Wien, Schnitzler traz para o centro das narrativas a mulher de seu tempo. De origem humilde ou burguesa, as 
personagens femininas expõem seus dramas amorosos - casamento, adultério, aborto, homossexualidade, prostituição.

\section{ALGUMAS QUESTÕES SOBRE A HISTERIA}

A feminilidade e a sexualidade feminina constituem dois grandes pilares teóricos da psicanálise do século XIX. Em Estudos sobre a Histeria (1895), enquanto se empenha em explicar os fenômenos mentais em termos fisiológicos e químicos; Freud confessa que seus casos clínicos têm a forma de contos e suas análises são psicológicas. Ainda em plena vigência do método catártico, Freud e Breuer (1842-1925) já evidenciavam a importância e a frequência da fantasia nos relatos das histéricas. Esse tipo de atividade mental ocorria muito frequentemente na histeria, não apenas nos estados de vigília, mas também na base de estados de ausência ou estados hipnóides.

Na verdade, o Método Catártico, como conceituado no início da história da Psicanálise, remete à palavra grega catarse, empregada por Aristóteles para designar o processo de purgação ou eliminação das paixões que se produz no espectador, no teatro, ao assistir à representação de uma tragédia. O termo foi introduzido nos Estudos sobre a Histeria, remetendo ao método terapêutico pelo qual um sujeito consegue eliminar seus afetos patogênicos, ao reviver os acontecimentos traumáticos a que eles estão ligados (LAPLANCHE \& PONTALIS, 1988, p. 107).

Com o abandono da teoria da sedução, tem-se a crença de que a histeria seria uma construção, em termos de fantasia, do próprio sujeito, “[...] uma fantasia que é apenas o produto e a máscara das manifestações espontâneas da atividade sexual infantil" (LAPLANCHE \& PONTALIS, 1988, p.25). Laplanche e Pontalis (1988), entendem a formulação 
da teoria da sedução como uma tentativa de Freud no sentido de estabelecer um vínculo entre a sexualidade, o traumatismo e a defesa, isto é, de conferir exclusivamente à sexualidade a capacidade de induzir o processo de defesa, de produzir o recalque.

Para o pensamento psicanalítico, a teoria da sedução inicialmente proposta por Freud como raiz dos sintomas histéricos, remete, antes de mais nada, à ideia de uma cena sexual em que um sujeito, geralmente adulto, vale-se de seu poder (real ou imaginário) para abusar de outro, reduzindo esta criança ou mulher, a um papel passivo. Dito de outra forma, a neurose teria origem num abuso sexual normal, a partir da inscrição de um trauma - a lembrança dos episódios de abuso seria tão penosa que todos preferem esquecê-lo (Idem, 1988, p. 696).

Em termos históricos, como salienta Leite (2012), a histeria, tratada por padres e médicos, encerra aquilo que desafia o discurso vigente, inscrevendo-se no corpo reprimido. Sendo assim, “(...) por suas múltiplas formas de expressão, a histeria parece se constituir num verdadeiro espelho da cultura, uma tela de projeção em que se fixa a imagem negada daquele que a contempla" (LEITE, 2012, p.85).

Freud desenvolveu seus estudos entre duas formas de histeria: a de angústia, cujo sintoma central é a fobia, e a de conversão, onde se exprimem através do corpo representações sexuais recalcadas.

No fenômeno da conversão, Freud observa a passagem de um conflito psíquico para sintomas somáticos, motores e sensitivos na busca de um alívio. A conversão seria, ainda, a caricatura de uma obra de arte (TAVARES, 1997, p.93). É nessa trilha que, posteriormente, 
Freud ligará às histéricas as ideias de fantasia ou fantasma (também aplicáveis às neuroses como um todo) - vividas intensamente num turbilhão de verdadeiros enredos internos.

A histérica das teorias freudianas vive em descompasso com a fôrma de feminilidade que lhe cabe; não se encaixa facilmente nos padrões da família nuclear e do lar burguês, cuja principal função, segundo Kehl (2016, p. 38), “(...) é promover o casamento, não entre a mulher e o homem, mas entre a mulher e o lar". Ainda de acordo com Kehl, a segunda importante função foi adequar a posição feminina a um modelo que sustentasse a virilidade do homem burguês. Contudo, os ideais de submissão feminina entram em choque com os valores de autonomia defendidos pelo homem moderno. A domesticidade contrapõe-se à liberdade; a vida predestinada ao casamento e à maternidade, à ideia moderna de que cada sujeito deve construir a sua história de acordo com a sua vontade. "Para cada mulher nascida no século XIX, e ainda hoje, apresenta-se a questão de ser um sujeito ou colocar-se como objeto do discurso do Outro, segundo os ideais de feminilidade constituídos no mesmo período (Ibidem)".

Sobre a participação no que Freud chama de "as grandes tarefas da cultura", é fato reconhecido a quase invisibilidade das mulheres, restando-Ihes poucas chances de sublimação por meio do dispositivo da Arte, desde sempre acessível aos homens. Nessa linha, o conhecido ensaio de Virginia Woolf, Um teto todo seu (1985), aponta o silêncio como um velho companheiro na história das mulheres. Para Woolf, qualquer mulher que tivesse demonstrado o talento de Shakespeare no século XVI teria certamente enlouquecido, se matado com um tiro, ou terminado seus dias em profundo isolamento, “meio bruxa, meio feiticeira, temida e ridicularizada" (WOOLF, 1985, p. 59). 


\section{FRÄULEIN ELSE E CRÔNICA DE UMA VIDA DE MULHER}

Antes de passarmos a alguns aspectos das novelas em questão, defende-se, aqui, o conceito de ficção não como algo oposto ou incongruente com a noção de verdade ou de realidade, mas sim um lugar privilegiado de produção de saberes. A literatura antecipa saberes, dá voz a discursos marginais, antes que se manifestem pelos canais tradicionais.

Lançado em 1924, Senhorita Else é uma obra que consagrou o estilo de monólogo interior, já adotado pelo escritor em 1900. Assim como Crônica de uma vida de mulher (1928), Senhorita Else acompanha o fluxo de pensamentos no curso de um único dia da jovem de 14 anos, Else, bela filha de uma família burguesa falida, hospedada num hotel no interior da Itália. Por meio de poucos diálogos e um frenesi de sensações, compartilhamos da angústia da personagem diante de seu destino possível. Fica claro o conflito da jovem com os membros da família, interessados em usá-la como uma espécie de isca, a fim de conseguir um casamento que rendesse dinheiro para a família. O ápice da tensão se dá quando Else aceita uma generosa quantia do Senhor Dorsday, em pagamento pela visão de sua nudez durante 15 minutos. Após intenso sofrimento, a jovem se posiciona, nua, no salão do Casino e, posteriormente, sofre um colapso nervoso.

Como já apontamos anteriormente, enquanto a Modernidade oferece novos ideais de liberdade individual, a mulher permanece presa ao seio do lar e da família, tendo como companhia a leitura de romances, os quais atuam como verdadeiros narcóticos. Therese, protagonista de Crônica de uma vida de mulher, alterna suas ocupações com a leitura sistemática dessa literatura:

A fim de expulsar o tédio, que várias vezes tomava conta dela, inscreveu-se em uma biblioteca de empréstimos que ficava no subúrbio, e sem escolher, mas 
sempre na expectativa e muitas vezes totalmente mergulhada em um mundo fantástico e trivial, ela devorava diversos volumes durantes as muitas horas que passava sozinha em sua câmara melancólica (SCHNITZLER, 2008, p.134).

Entre as aventuras amorosas e até ao contrair a gravidez, a personagem demonstra total descompasso e desligamento da realidade a sua volta, movendo-se ao sabor dos ventos de seus desejos imediatos. A gravidez indesejada, fruto de uma relação sem envolvimento amoroso, inicia o processo de estigmatização e decadência da personagem como mãe solteira e presa, mais do que nunca, a um círculo vicioso de trabalho, através do qual sustenta o filho, além de fazê-la menos tentadora aos olhos da moral da época, que a reconhece como uma mulher liberada sexualmente.

No romance Crônica de uma vida de mulher, o corpo feminino existe somente para o olhar e desfrute do Outro. Therese se entrega a vários homens somente para sentir-se desejada, respondendo com indiferença. Trata-se de um corpo "objetificado", instrumentalizado.

Assim como Therese, Else também devora romances, sobretudo os franceses. Quanto ao sexo masculino, ela, a todos deseja, mas a ninguém, já que suas divagações giram em torno de seu poder de sedução, usufruindo de sua inesgotável fantasia. Ela é, igualmente, presa do desejo de todos os homens, porém, admite não conhecer o amor.

A novela se inicia com um jogo de tênis, e esse episódio pode ser lido como uma metáfora para o jogo que Else estabelece com as pessoas, principalmente os homens. Sonha com um casamento próspero, ao mesmo tempo que o cerca de erotismo: “(...) gostaria de me casar nos Estados Unidos, mas não com um americano. Ou então caso-me com um 
americano e vivemos na Europa. Numa mansão na Riviera. Degraus de mármore até o mar. Eu me estenderia nua sobre o mármore. (...)" (Idem, p. 8).

\section{CONSIDERAÇÕES FINAIS}

Freud e Schnitzler exploram, cada um à sua maneira, o sujeito e suas vicissitudes. Por esse motivo, a sexualidade e a morte entrelaçam-se às trajetórias das personagens fictícias, assim como às teses freudianas. Schnitzler e Freud partem da medicina e se inserem num campo discursivo. O segundo funda a Psicanálise, a talking cure (cura ou tratamento pela fala), o primeiro abandona o exercício da medicina e torna-se o Doktor-Dichter (DoutorPoeta), como era conhecido na capital austríaca. O discurso sobre o sujeito mulher é o ponto de chegada/partida da obra dos autores aqui abordados, que, assim como suas biografias, testemunha a dialética entre o científico e o estético.

A ideia de que o envolvimento sexual leva à destruição é o tema central na obra de Schnitzler. Tendo se aproximado do sexo feminino por conta de várias conquistas, retirou de sua vida o retrato para muitas de suas personagens. A literatura de Schnitzler serve como possível guia para o leitor em busca da Viena de Freud.

Conceito central em nossa argumentação, a Histeria atingiu em cheio o mundo literário. Não resta nada ao corpo histérico a não ser alienar-se de si mesmo. O desfecho da novela Senhorita Else corrobora esse aspecto, trazendo a questão da nudez destinada ao olhar masculino; verdadeira moeda de troca. Ao oferecer-se como pagamento, Else entra em colapso. Em Crônica de uma vida de mulher, Therese transita entre flertes e relações superficiais, à medida que o desejo do Outro a solicita. Esvaziada de seu próprio desejo, torna-se presa de uma gravidez inesperada; encarcera-se na maternidade solitária e na luta 
para se sustentar financeiramente, encontrando o desfecho para um destino de mulher sem perspectivas.

Nos estudos freudianos, a partir das histéricas, a cura pela fala institui o paradigma psicanalítico; a fantasia toma o lugar da sedução, mesmo terreno do qual se alimentam poetas e escritores. Tomando a literatura como espaço possível de saberes dramatizados, ela dá voz à sua época, assim como aos sujeitos, mulheres aprisionadas pelas paredes do lar burguês.

\section{REFERÊNCIAS}

FREUD, Sigmund. Estudos Sobre a Histeria. 1893-1895 - Vol. 2. Coleção Obras Completas. Trad. Laura Barreto. Companhia das Letras.

Totem e Tabu. Contribuição à História do Movimento Psicanalítico e outros textos. 1912-1914. Vol. 11. Trad. Paulo Cesar de Souza. Companhia das Letras.

O Inquietante. 1917-1920. Vol. 14. História de uma Neurose Infantil (O Homem dos Lobos), Além do Princípio do Prazer e outros textos. Trad. Paulo César de Souza. Coleção Obras Completas. Companhia das Letras.

HOFMANN, Paul. Os Vienenses: esplendor, decadência e exílio. Trad. Raul de Sá Barbosa. Rio de Janeiro: José Olympio, 1996.

KANAAN, H. S. Resenha O fim da história e o último homem. In: Percursos. Santa Catarina, v. 6, n. 1, pp. 1-10, 2005. Disponível em http://www.periodicos.udesc.br/index.php/percursos/article/viewFile/1451/1224. Download em 10 de agosto de 2018.

KEHL, Maria Rita. Desdobramentos do Feminino: a mulher Freudiana na passagem da modernidade. 2. ed. São Paulo: Boitempo, 2016.

LACAN, J. O seminário, livro 17: o avesso da psicanálise. Rio de Janeiro: Jorge Zahar, 1969$1970 / 1992$.

LAPLANCHE, J. \& PONTALIS, J.-B. Fantasia Originária, Fantasias das Origens, Origens da Fantasia. Rio de Janeiro: Jorge Zahar Editor; 1988, (1964).

LEITE, S. Histeria de conversão: algumas questões sobre o corpo na psicanálise. In: Tempo Psicanalítico. Rio de Janeiro, v. 44.i, 2012, pp. 83-102. Disponível em 
http://pepsic.bvsalud.org/pdf/tpsi/v44n1/v44n1a06.pdf. Download em 17 de junho de 2017.

LE RIDER, Jacques. A Modernidade Vienense e as crises de identidade. Trad. de Elena Gaidano. Rio de Janeiro: Civilização Brasileira, 1993.

ROUDINESCO, Elisabeth. Por que a Psicanálise? Rio de Janeiro: Zahar, 2000.

SCHORSKE, Carl E. Viena fin-de-siècle: política e cultura. Trad. Denise Bottmann. São Paulo: Companhia das Letras, 1988.

TAVARES, Pedro Heliodoro de Moraes Branco. Freud \& Schnitzler. Sonho sujeito ao olhar. São Paulo: Annablume, 2007.

SCHNITZLER, Arthur. Senhorita Else. Trad. Marijane Lisboa. Rio de Janeiro: Paz \& Terra, 1985 (1924).

. Crônica de uma vida de mulher. Trad. Marcelo Backes. Rio de Janeiro: Record, 2008 (1928).

WOOLF, Virginia. Um teto todo seu. Trad. Vera Ribeiro. Rio de Janeiro: Nova Fronteira, 1985.

Artigo recebido em: 07 de maio de 2018. Artigo aprovado em: 12 de julho de 2018. 